\title{
Escrita acadêmica: a resenha como produto de retextualização
}

Anne Carolline Dias Rocha Prado*

Márcia Helena de Melo Pereira**

\section{Resumo}

Neste artigo, aborda-se a resenha acadêmica como um produto de retextualização. Ancorados em Marcuschi (2010) e Matencio (2002), compreende-se a retextualização como um processo de transformação de um texto em outro, que envolve aspectos linguísticos, textuais, discursivos e cognitivos. Dessa forma, objetiva-se descrever as operações textuais e discursivas envolvidas no processo de retextualização de um curta-metragem para a escrita de uma resenha acadêmica. Para isso, será utilizada uma resenha acadêmica escrita por uma dupla de estudantes universitários, e seus dados processuais, a partir do curta metragem Vida Maria. As análises mostraram que, na resenha analisada, os sujeitos estabeleceram uma relação com o curta metragem, ao mesmo tempo em que se posicionaram como avaliadores da obra, mantendo, para isso, um vínculo com a estrutura retórica do gênero e com o texto-base.

Palavras-chave: Escrita acadêmica. Resenha. Retextualização.

\section{Introdução}

O objetivo deste artigo é descrever as operações textuais e discursivas envolvidas no processo de retextualização de um curta-metragem para a escrita de uma resenha acadêmica.

Entendemos a retextualização a partir de Matencio (2002) e Marcuschi (2010), que definem o processo como sendo a reformulação de um texto, na qual ocorrem variações de gêneros textuais, objetivos, estilos e níveis linguísticos. Em outras palavras, a retextualização é a produção de um novo texto a partir de um ou mais textos-base; é dizer de outra maneira, em outro gênero e/ou em outra modalidade o que já foi dito ou escrito por alguém. Dessa maneira, uma vez que

\footnotetext{
" Mestranda do Programa de Pós-graduação em Linguística da Universidade Estadual do Sudoeste da Bahia (Uesb). E-mail: annerochaprado@gmail.com

** Doutora em Linguística Aplicada pela Universidade Estadual de Campinas (Unicamp). Professora adjunta do Departamento de Estudos Linguísticos e Literários (Dell), e docente do quadro permanente do Programa de Pós-Graduação em Linguística (PPGLin), ambos da Universidade Estadual do Sudoeste da Bahia (Uesb), campus de Vitória da Conquista. E-mail: marciahelenad@yahoo.com.br
}

Data de submissão: fev. 2018 - Data de aceite: jun. 2018 http://dx.doi.org/10.5335/rdes.v14i2.7992 
a resenha acadêmica é uma produção linguística, textual e discursiva que modifica um texto, encaramos este gênero como um produto de retextualização.

Para isso, utilizaremos uma resenha acadêmica escrita por duas estudantes universitárias, do curso de Ciência da Computação, da Universidade Estadual do Sudoeste da Bahia, bem como trechos da conversa mantida pela dupla enquanto produzia o texto. A resenha foi elaborada a partir do curta metragem Vida Maria, dirigido por Márcio Ramos, em 2006.

Via de regra, as análises textuais empreendidas por pesquisas linguísticas têm considerado o produto final escrito, o texto. $\mathrm{O}$ grande diferencial do nosso trabalho é o fato de utilizarmos dados processuais - o diálogo da dupla ao produzir o texto, que nos mostra as várias operações distintas e sucessivas realizadas pelos sujeitos durante a produção, tais como: escolhas vocabulares em detrimento de outras, acréscimos de palavras, apagamentos, inversões da ordem de enunciados etc.; uma entrevista feita com as estudantes questionando-as a respeito das operações que realizaram, na qual elas próprios puderam explicar por que apagaram, por que substituíram e assim por diante; o rascunho e o texto pronto. Esses dados nos permitem compreender a relação que as escreventes mantêm com o texto, com o gênero e com o discurso que o envolve e, portanto, compreender melhor a relação do sujeito com a linguagem.
Uma vez que sempre enunciamos tomando por base um gênero do discurso, seu conceito é fundamental para se discutir qualquer questão relacionada a textos. A definição que adotaremos é a postulada por Bakhtin (2011).

A noção de gênero, segundo o filósofo russo, reporta ao funcionamento da língua em práticas comunicativas, reais e concretas, construídas por sujeitos que interagem nas esferas das relações humanas e da comunicação. Essa interação social produz enunciados concretos e únicos, de acordo com as condições específicas e as finalidades de cada esfera da atividade humana. Cada enunciado se liga a outros pela identidade da esfera de comunicação discursiva da qual faz parte, e cada esfera "elabora seus tipos relativamente estáveis de enunciados" (BAKHTIN, 2011, p. 262, grifo do autor), chamados gêneros do discurso. Uma dessas esferas é a acadêmica. Ela constitui uma instância discursiva autônoma, que é capaz de produzir suas próprias exigências e de influenciar outras instâncias que a cercam e elaborar diferentes gêneros discursivos, como a resenha, por exemplo.

Vale acrescentar que, conforme os postulados bakhtinianos, os gêneros do discurso podem ser classificados como primários ou secundários. Os primários são aqueles considerados mais simples, como os gêneros orais; os secundários, por sua vez, são aqueles de elaboração mais complexa, por possuírem um caráter mais padronizado no meio cultural, envolvendo a maioria dos gêneros escri- 
tos. Dessa forma, podemos considerar que a resenha é um gênero secundário, diante da maior complexidade e padronização em sua elaboração.

Neste artigo, conceituamos e caracterizamos o gênero dentro do qual nossas escreventes trabalham a partir de Motta-Roth e Hendgens (2010) e Motta-Roth (1995 apud MOTTA-ROTH, 2002), para quem a resenha é um gênero utilizado na universidade para avaliar uma produção intelectual de determinada área do conhecimento. Além disso, nos reportamos às concepções de Araújo (2002), Machado (2005) e Silva e Matencio (2003) para refletirmos a respeito desse gênero.

Ainda, para corroborar a ideia de que a resenha acadêmica é um produto de retextualização, visto que se trata de uma produção linguística, textual e discursiva que modifica um texto devidamente compreendido, adotamos o posicionamento de Souza e Silva (2017) a esse respeito.

A partir dessas considerações, buscamos verificar de que maneira uma dupla de estudantes universitários estabelece uma relação com o curta metragem, a partir de estratégias linguísticas, textuais e discursivas com as quais ela constrói a macroestrutura de sua resenha acadêmica.

\section{(Re)textualização: uma prática de escrita}

Uma vez que, neste artigo, o gênero que investigaremos, a resenha acadêmica, é tomado como produto de retextuali- zação, precisamos entender o que é essa prática e como ela funciona. Portanto, a noção de retextualização será a principal norteadora de toda nossa discussão.

A atividade de retextualização é uma das práticas de escrita mais desenvolvidas no âmbito acadêmico, visto que os gêneros dessa esfera ou possuem um caráter científico, pautado no já dito, no discurso do outro, ou são resultados de textos previamente produzidos. Dessa forma, a escrita acadêmica se configura como um terreno fértil para investigações acerca desse tipo de produção escrita, embora não sejam muitos os trabalhos desenvolvidos sobre o assunto. É por essa razão que nos interessamos pela investigação de retextualização em práticas acadêmicas.

Ancorados em Matencio (2002) e Marcuschi (2010), entendemos a retextualização como a reformulação de um texto, na qual ocorrem variações de gêneros textuais, objetivos, estilos e níveis linguísticos. Trata-se da produção de um novo texto a partir de um ou mais textos-base, ou seja, dizer de outra maneira, em outro gênero e/ou em outra modalidade o que já foi dito ou escrito por alguém.

Segundo Matencio (2002), retextualizar envolve tanto relações entre gêneros e textos (intertextualidade) quanto relação entre discursos (interdiscursividade), o que significa que são observadas, na materialidade textual, as manifestações de operações propriamente linguísticas, textuais e discursivas. Para a autora, a 
retextualização exige conhecimento sobre diferentes aspectos estruturais e linguísticos do texto-base e dos mecanismos enunciativos de gerenciamento de vozes, necessários à produção do novo texto, o que significa não apenas expor as ideias de outros autores, mas estabelecer uma relação de concordância ou discordância entre discursos e textos. Nas palavras da linguista:

[...] na retextualização, [...] opera-se, fundamentalmente, com novos parâmetros de ação da linguagem, porque se produz novo texto: trata-se, além de redimensionar as projeções de imagem dos interlocutores, de seus papéis sociais e comunicativos, dos conhecimentos partilhados, assim como de motivações e intenções, de espaço e tempo de produção/recepção, de atribuir novo propósito à produção linguageira (MATENCIO, 2002, p. 113).

Como podemos observar, para Matencio (2002), as condições de produção e os propósitos comunicativos constituem variáveis determinantes para a produção do novo texto, para o resultado final da retextualização.

Ainda, de acordo com Marcuschi (2010), as atividades de retextualização são altamente automatizadas, e lidamos com elas o tempo todo, já que fazemos sucessivas reformulações dos mesmos textos a todo momento. Todavia, isso não quer dizer que retextualizar seja um processo mecânico; ao contrário, é um "processo que envolve operações complexas que interferem tanto no código como no sentido" (MARCUSCHI, 2010, p. 46) e requer inevitavelmente a compreensão do texto-base.
Vale salientar que, segundo Matencio (2002) e Marcuschi (2010), retextualizar não se confunde com reescrever, embora ambas envolvam operações linguísticas similares, como, por exemplo, adição, supressão, substituição e reordenação tópica. Todavia, no que se refere às operações textuais e discursivas, as diferenças são maiores, e as variáveis que interferem em cada um se comportam de maneira diferente.

Marcuschi (2010, p. 54) aponta quatro variáveis que interferem na retextualização: 1) o propósito ou objetivo da retextualização; 2) a relação entre o produtor do texto original e o transformador; 3 ) a relação tipológica entre o gênero textual original e o gênero da retextualização; 4) os processos de formulação típicos de cada modalidade da língua.

A primeira variável está relacionada às escolhas relativas ao conteúdo temático do texto-base e o que se pretende preservar. A depender da finalidade da reformulação, é possível que haja uma grande diferença no nível de linguagem do texto.

Para explicar a segunda variável, o autor afirma que, caso o retextualizador seja também o autor do texto-base, provavelmente, as mudanças serão mais drásticas, tanto na forma quanto no conteúdo do texto; do contrário, quando alguém, que não o autor, retextualiza 0 texto, o número de mudanças no conteúdo será menor, embora as mudanças na forma possam ser acentuadas. 
A variável seguinte está relacionada à mudança de gênero. É possível dizer que, quando há mudança do gênero do texto-base para outro gênero na retextualização, as modificações são mais radicais do que quando o gênero do texto original é mantido.

Por fim, a última variável diz respeito às estratégias de produção textual ligadas à cada modalidade da língua (modalidade oral, modalidade escrita). Nessa perspectiva, Matencio (2002) reforça:

Ora, se retextualizar é produzir um novo texto, então se pode dizer que toda e qualquer atividade propriamente de retextualização irá implicar, necessariamente, mudança de propósito, porque não se trata mais de operar sobre o mesmo texto, para transformá-lo - o que seria o caso na reescrita -, mas de produzir novo texto (MATENCIO, 2002, p. 112-113).

Do ponto de vista de Matencio (2002), as atividades de retextualização englobam tanto a apropriação de conceitos e procedimentos acadêmico-científicos ( $\mathrm{s} a$ ber fazer), quanto de modos de referência e de textualização dos saberes (saber dizer). Dessa forma, analisar a retextualização de textos acadêmico-científicos compreende reflexão sobre questões relativas à construção do próprio objeto de estudo, bem como ao funcionamento dos gêneros discursivos e às práticas discursivas nas quais eles circulam.

\section{A resenha: um gênero da esfera acadêmica que é retextualizado}

Para tratar da produção do gênero que interessa a este trabalho, a resenha, é preciso adotarmos um conceito de gênero e caracterizar o gênero que será trabalhado.

O conceito de gênero com o qual trabalharemos é o postulado pelo teórico russo Mikhail Bakhtin, em seu ensaio "Os gêneros do discurso".

Para Bakhtin (2011), a linguagem tem como objetivo a comunicação entre o eu e o outro, entre of falante e o ouvinte. Segundo o autor, a real unidade da comunicação discursiva é o enunciado, construído a partir de atitudes responsivas do falante e do ouvinte. Assim, o enunciado é delimitado pela alternância dos sujeitos do discurso. De acordo com Bakhtin, seja uma réplica do diálogo cotidiano, seja um grande romance ou tratado científico, todo e qualquer enunciado possui um início absoluto e um fim absoluto:

[...] antes do seu início, os enunciados de outros; depois do seu término, os enunciados responsivos de outros (ou ao menos uma compreensão ativamente responsiva silenciosa do outro ou, por último, uma ação responsiva baseada nessa compreensão). $O$ falante termina o seu enunciado para passar a palavra ao outro ou dar lugar à sua compreensão ativamente responsiva (BAKHTIN, 2011, p. 275). 
Portanto, o enunciado deve ser visto como um elo da cadeia comunicativa e da relação com outros enunciados veiculados a ele. Esses enunciados conhecem uns aos outros e se refletem uns nos outros, e cada um possui em seu todo ecos e ressonâncias de outros enunciados. Cabe ainda dizer que um enunciado se liga a outros pela identidade da esfera de comunicação discursiva da qual faz parte.

Relacionados aos enunciados estão os gêneros do discurso. Conforme Bakhtin (2011), a linguagem atravessa todas as esferas da atividade humana, produzindo enunciados concretos e únicos, de acordo com as condições específicas e as finalidades de cada uma dessas esferas - os gêneros do discurso.

Considerando a diversidade dos campos da atividade comunicativa, o filósofo define gêneros do discurso como tipos relativamente estáveis de enunciados, que possuem, em seu todo, três elementos indissoluvelmente ligados: o conteúdo temático, o estilo e a construção composicional. Nas palavras de Bakhtin:

Todos os diversos campos da atividade humana estão ligados ao uso da linguagem. [...] O emprego da língua efetua-se em forma de enunciados (orais e escritos) concretos e únicos, proferidos pelos integrantes desse ou daquele campo da atividade humana. Esses enunciados refletem as condições específicas e as finalidades de cada referido campo não só por seu conteúdo (temático) e pelo estilo da linguagem, [...] mas, acima de tudo, por sua construção composicional. [...] cada campo de utilização da língua elabora seus tipos relativamente estáveis de enunciados, os quais denominamos gêneros do discurso (Bakhtin, 2011, p. 261-262).
De acordo com o teórico, toda e qualquer atividade comunicacional só é possível por meio de gêneros discursivos. A intenção discursiva do discurso ou a vontade discursiva do falante se realizam, antes de tudo, a partir da escolha de determinado gênero do discurso ${ }^{1}$ e, uma vez que a atividade humana é inesgotável, a riqueza e a diversidade dos gêneros do discurso são infinitas e utilizamos um vasto repertório com segurança e habilidade, muitas vezes até de maneira inconsciente, pois os gêneros chegam à nossa experiência e à nossa consciência quase da mesma forma que a língua materna: por meio da comunicação discursiva viva.

Cabe destacar, também, a classificação em gêneros primários e secundários apresentada por Bakhtin (2011), considerando a "extrema heterogeneidade dos gêneros discursivos e a dificuldade daí advinda de definir a natureza geral do enunciado" (BAKHTIN, 2011, p. 263). Segundo o autor, os gêneros secundários apresentam uma estrutura mais desenvolvida e organizada, em geral são escritos e surgem nas condições mais complexas da comunicação discursiva. Já os gêneros primários se desenvolvem nas situações mais imediatas da comunicação e estão mais próximos da oralidade. Bakhtin chama a atenção para o fato de a alternância dos sujeitos no discurso ser mais simples e evidente nos gêneros secundários, e parecer não existir nos gêneros secundários. Para ele, isso acontece porque, com frequência, "o fa- 
lante (ou quem escreve) coloca questões no âmbito do seu enunciado, responde a elas mesmas, faz objeções a si mesmo e refuta suas próprias objeções, etc." (BAKHTIN, 2011, p. 276). Todavia, para o filósofo russo, os gêneros secundários sempre se valem dos discursos primários e as relações entre eles. Portanto, "esses fenômenos [que acontecem nos gêneros secundários] não passam de representação convencional da comunicação discursiva nos gêneros primários do discurso" (BAKHTIN, 2011, p. 276).

Nesse sentido, é válido destacarmos um aspecto: os gêneros do discurso refletem as condições específicas e as finalidades de cada esfera de utilização da língua. No caso dos gêneros produzidos na esfera acadêmica, em sua maioria secundários, como a resenha, podemos reconhecê-los pela maneira particular com que são constituídos, principalmente no que diz respeito ao tema e ao objetivo, ao público alvo e à natureza e à organização das informações incluídas (MOTTA-ROTH; HENDGES, 2010). Em outras palavras, os gêneros acadêmicos costumam apresentar uma configuração típica e são identificados com facilidade por seus aspectos discursivos e estrutura retórica.
A resenha é um gênero bastante solicitado no âmbito acadêmico e é definido por Motta-Roth e Hendges (2010) como um gênero discursivo utilizado para dar uma opinião crítica sobre determinada produção. Segundo as pesquisadoras, uma resenha atinge por volta de 1500 palavras e, normalmente, é desenvolvida em quatro partes: 1) apresentação; 2) descrição; 3) avaliação; 4) (não) recomendação. Essas partes, geralmente, aparecem nessa ordem e podem variar em tamanho e frequência e, ainda, várias estratégias retóricas podem ser empregadas na produção de cada uma. As autoras afirmam, também, que uma resenha é, ao mesmo tempo, avaliativa e informativa, já que, apesar de a avaliação ser a função que define o gênero, é possível incluir informações ilustrativas para criticar ou elogiar o que está sendo resenhado.

Motta-Roth (1995² apud MOTTA-ROTH, 2002) apresenta uma descrição esquemática do gênero resenha que envolve quatro movimentos retóricos realizados por dez estratégias retóricas. Vejamos esse esquema: 
Figura 1 - Descrição esquemática da organização em resenhas acadêmicas

\begin{tabular}{|c|c|}
\hline Movimento 1 & APRESENTANDO O LIVRO \\
\hline Passo 1 & 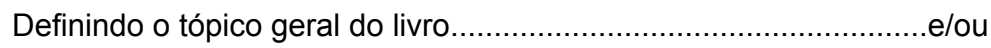 \\
\hline Passo 2 & Informando sobre a virtual audiência.................................... \\
\hline Passo 3 & Informando sobre o/a autor/a................ \\
\hline Passo 4 & 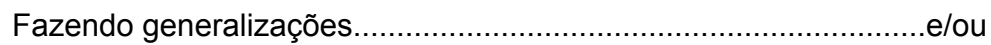 \\
\hline Passo 5 & Inserindo o livro na área \\
\hline Movimento 2 & ESQUEMATIZANDO O LIVRO \\
\hline Passo 6 & Delineando a organização geral do livro......................................eu \\
\hline Passo 7 & Definindo o tópico de cada capítulo...............................................e/ou \\
\hline Passo 8 & Citando material extratexto \\
\hline Movimento 3 & RESSALTANDO PARTES DO LIVRO \\
\hline Passo 9 & Avaliando partes específicas \\
\hline Movimento 4 & FORNECENDO AVALIAÇÃO FINAL DO LIVRO \\
\hline Passo 10A & Recomendando/desqualificando o livro.............................. \\
\hline Passo 10B & Recomendando o livro apesar das falhas \\
\hline
\end{tabular}

Fonte: Motta-Roth, 1995 apud Motta-Roth, 2002, p. 93.

De acordo com a autora, essa descrição revela que o escritor de uma resenha avalia novas produções contextualizando a obra, descrevendo e avaliando pontos específicos e recomendando ou não o material, e cada movimento realizado é, normalmente, delimitado por parágrafos.

Para Machado (2005), uma resenha acadêmica é produzida a partir de uma atividade de leitura que implica interpretação e sumarização dos conteúdos, o que significa dizer que resumir com eficácia é essencial para resenhar. Com isso, o escritor da resenha mobiliza outras obras que lhe permitirão comparar e avaliar o que está sendo resenhado. De acordo com a autora, é preciso considerar que existe a possibilidade de o leitor ter uma opinião contrária ao do resenhista e, por isso, é preciso apresentar argumentos que validem seu posicionamento. Nesse sentido, Araújo (2002) afirma que, por seu caráter argumentativo, a resenha é perpassada por várias vozes, por diversas estratégias linguísticas utilizadas para dar credibilidade e autoridade à voz do enunciador, ou seja, na resenha, o enunciador incorpora à sua enunciação pontos de vista de diversos enunciadores.

Segundo Lima-Silva (2011), na resenha acadêmica, o escritor se refere ao autor da obra resenhada ou à própria obra. Para isso, utiliza mecanismos de textualização, como a repetição do nome completo do autor, de uma parte, pelo apagamento ou pela substituição por o autor, o pesquisador, o estudioso, a indicação do título do livro no início e a 
retomada por meio de expressões como a obra, o estudo, o trabalho. Além disso, o autor da resenha faz uso de verbos que atribuem ações ao produtor da obra ou à obra como, por exemplo, examina, classifica, comenta, propõe, e, ainda emprega expressões que orientam o leitor quanto à organização da produção, como inicialmente, a seguir, ainda, por fim. $\mathrm{E}$, ainda, a resenha é constituída por ideias do resenhista e do produtor da obra, que são diferenciadas pelo uso de termos como segundo $x, x$ diz que, $x$ sustenta que, seguido de paráfrase ou citação.

Ainda, Silva e Matencio (2003) afirmam que, na configuração textual da resenha, há modos de dizer que refletem os movimentos que o autor mobiliza para promover o chamado gerenciamento de vozes. Isso porque a resenha é um gênero que pressupõe diálogo com a obra resenhada e/ou com diferentes obras, ou seja, "na tessitura do texto, pode instaurar-se uma conjunção de vozes (locutores/ enunciadores) que deixam revelar os pontos de vista, a formação discursiva, as crenças que reportam a modos de ver e recortar o mundo" (SILVA; MATENCIO, 2003, p. 3-4).

Nessa perspectiva, encaramos a resenha acadêmica como um produto de retextualização, visto que se trata de uma produção linguística, textual e discursiva que modifica um texto devidamente compreendido, a partir de posicionamentos avaliativos de um enunciador que precisa se posicionar como crítico de uma obra.

Souza e Silva (2017) corroboram o que estamos dizendo. Para as autoras, resenhas acadêmicas são retextualizações, porque são escritas a partir de um texto base e transportam e veiculam seu conteúdo temático, sendo influenciadas pelo contexto de produção. Esse processo é ilustrado pelas autoras da seguinte maneira:

Figura 2: O gênero retextualizado resenha

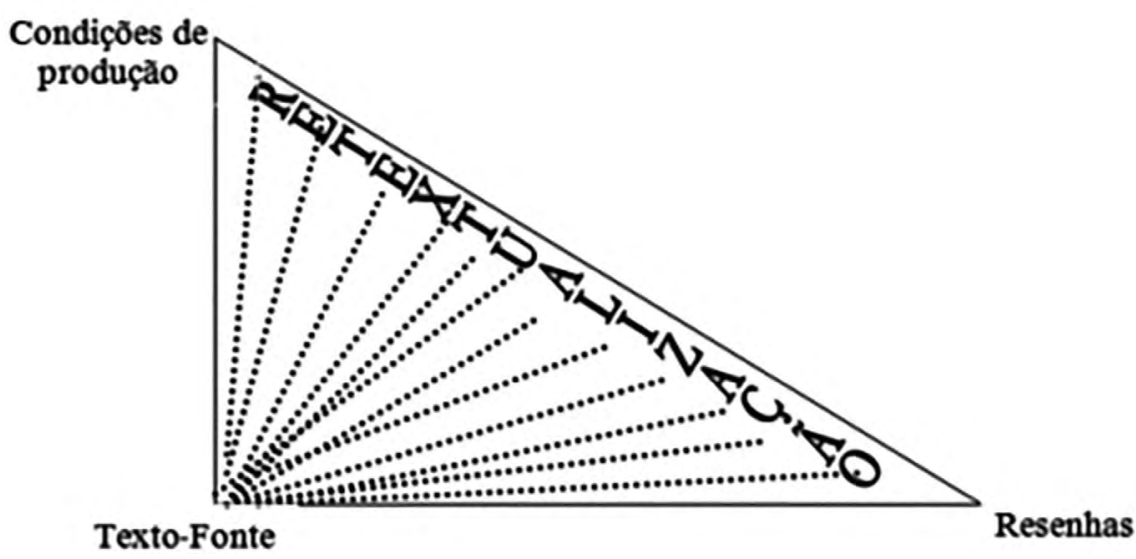

Fonte: Souza; Silva (2017, p. 69). 
De acordo com as pesquisadoras, a produção de resenhas envolve um contínuo de compreensão, descrição e apreciação de uma obra, e a retextualização se concretiza com a terceira etapa, a apreciação. A compreensão do texto-base é um nível mais abstrato do processo de retextualizar e é recuperado no texto por meio de pistas linguísticas; a descrição e a apreciação do texto base são níveis que perpassam todo o processo e revelam o posicionamento crítico sobre o texto-base.

\section{Procedimentos metodológicos}

Conforme mencionamos na nota 1 , ao final do texto, os dados que utilizaremos fazem parte de um corpus pertencente ao projeto de pesquisa "A relação entre estilo e gênero visto sob a perspectiva processual: desvendando os segredos da criação" - área de Linguística de Texto - coordenado pela Profa. Dra. Márcia Helena de Melo Pereira (Uesb/PPGLin).

Analisaremos uma resenha produzida por uma dupla de estudantes universitárias, do curso de Ciências da Computação, da Universidade Estadual do Sudoeste da Bahia, bem como trechos da transcrição da gravação em áudio da conversa mantida por essa dupla no momento da produção da resenha. A resenha foi escrita a partir do curta metragem Vida Maria, dirigido por Márcio Ramos, em 2006. Com duração de nove minutos, o curta conta a história de
Maria José, uma menina que, aos cinco anos de idade, é levada a largar os estudos para trabalhar e ajudar nos afazeres domésticos e, assim, ela cresce, casa, tem filhos e envelhece, repetindo essa história familiar ininterruptamente.

Como dissemos anteriormente, o grande diferencial do nosso trabalho é o fato de utilizarmos dados processuais, mas registrá-los não é tarefa fácil. Para isso, adotamos alguns procedimentos metodológicos.

Inicialmente, fizemos a opção pela escrita conjunta, para que pudéssemos gravar a conversa que a dupla manteria entre si durante a elaboração dos textos. Com esta gravação, teríamos acesso às dúvidas que tiveram, às escolhas linguísticas que empreenderam, as reformulações orais que não chegaram a ser textualizadas etc.

A dupla deveria assistir ao curta metragem e, em seguida, escrever sua resenha. Solicitamos às escreventes que não apagassem as modificações que fizessem na primeira versão do texto. Por último, as estudantes deveriam "passar o texto a limpo". Vale destacar que todo o momento da produção textual foi registrado em áudio.

$\mathrm{Na}$ etapa seguinte, ouvimos a gravação em áudio e pontuamos todos os episódios de reescrita encontrados, com base nas duas versões do texto, e, assim, anotados todas as situações que nos chamaram a atenção durante a conversa que a dupla manteve entre si, mas que não chegaram a ser escritas. Em seguida, 
elaboramos perguntas para fazermos à dupla.

Uma semana após a elaboração da resenha, fizemos a entrevista com as duas estudantes, questionando-as a respeito das operações que realizaram. Dessa forma, as próprias escreventes nos disseram por que apagaram, por que substituíram, e assim por diante. Essa entrevista também foi registrada em áudio.

Por último, transcrevemos todas as duas gravações, para facilitar o trabalho de análise dos dados.

\section{As operações de retextualização na resenha acadêmica em investigação}

Passemos, então, a observar de que maneira a dupla estabelece uma relação com o curta metragem, a partir das estratégias linguísticas, textuais e discursivas com as quais ela constrói a macroestrutura textual de sua resenha. Primeiramente, vejamos, no Exemplo 1, a resenha que as escreventes produziram:

Exemplo 1: Resenha produzida pela dupla de Ciência da Computação

O curta metragem Vida Maria, ganhador do $3 \square$ Prêmio Ceará de Cinema e Vídeo, trata-se de uma animação, produzida por VIACG, em que, com tons quentes e marcantes, retrata a triste realidade das Marias do sertão brasileiro.

Esta animação, que com seus aproximados 9 minutos, descreve a vida de Maria José, protagonista da história, que ainda quando criança, demonstra interesse pelos estudos e, devido a falta de esclarecimento da mãe, é obrigada a se submeter aos duros trabalhos rurais e domésticos para assim, garantir a sua, e a sobrevivência de sua família.

Maria é o símbolo de uma sociedade oprimida pelo Estado, que, devido ao seu desprovido grau econômico, crítico e cultural, tem por consequência, uma frustração e uma acomodação incapaz de dar novos rumos à história social.

Com brilhante clareza de expressão, Márcio Ramos, roteirista do curta, proporciona ao espectador, uma profunda e analítica reflexão, através do interminável ciclo das Maria.

No Exemplo 1, a dupla inicia a resenha apresentando e caracterizando a obra - O curta metragem Vida Maria, ganhador do $3^{\circ}$ prêmio Ceará de Cinema e Vídeo, trata-se de uma animação, produzida por VIACG, em que, com tons quentes e marcantes - e descrevendo o que seria, ao seu ver, a proposta do texto-base - retrata a triste realidade das Marias do sertão brasileiro. No parágrafo seguinte, as escreventes apresentam mais uma informação a respeito do vídeo - Esta animação, que com seus aproximados 9 minutos - e mais uma proposição - descreve a vida de Maria José, protagonista da história -, e, então, narram, quase fielmente, a história retratada no curta metragem - ainda quando criança, demonstra interesse pelos estudos e, devido a falta de esclarecimento da mãe, é obrigada a se submeter aos duros trabalhos rurais e domésticos para assim, garantir 
a sua, e a sobrevivência de sua família. Adiante, a dupla acresce um parágrafo reflexivo, que revela uma relação menos explícita com o texto-base - Maria é o símbolo de uma sociedade oprimida pelo Estado, que, devido ao seu desprovido grau econômico, crítico e cultural, tem por consequência, uma frustração $e$ uma acomodação incapaz de dar novos rumos à história social. As estudantes, então, finalizam avaliando a obra-Com brilhante clareza de expressão -, revelando mais informações - Márcio Ramos, roteirista do curta - apresentando mais uma proposição - proporciona ao espectador uma profunda e analítica reflexão, através do interminável ciclo das Marias.

Considerando os níveis de retextualização de uma resenha apontados por Souza e Silva (2017), podemos dizer que, nesta resenha, sobressai a descrição do conteúdo do texto-base, embora, em diversos momentos essa descrição se inter-relacione com a apreciação da dupla resenhista sobre ele, tendo, inclusive, um parágrafo apenas de apreciação, o terceiro parágrafo. Ao dizer, por exemplo "com tons quentes e marcantes, retrata a triste realidade das Marias do sertão brasileiro" e "Com brilhante clareza de expressão, Márcio Ramos, roteirista do curta, proporciona ao espectador, uma profunda e analítica reflexão", a dupla imbrica os dois níveis ao descrever e avaliar a obra ao mesmo tempo.

Vejamos, agora, trechos da conversa mantida pela dupla, em que as escreventes comentam a respeito do que devem colocar em cada parte do texto.
Se levarmos em consideração os postulados bakhtinianos, o que veremos nos dados apresentados a seguir é o processo de comunicação discursiva que ocorre entre dois sujeitos socialmente organizados, que realizam um diálogo contínuo entre si e com outros discursos. Como poderemos observar, as escolhas feitas pelas estudantes, em cada parágrafo, em primeiro lugar, demostram que elas se preocupam com onde, como e quando deveriam colocar elementos linguísticos típicos da resenha acadêmica, respeitando a estrutura retórica do gênero; em segundo lugar, essas escolhas estabelecem um vínculo efetivo com o texto-base: mesmo sem conhecer o vídeo, o leitor já consegue identificá-lo:

M: Na introdução. O que que se faz na introdução de resenha?

ML: Fala sobre a obra.

M: Sobre os autores da obra... Identifica a obra...

M: a pessoa tem que dar informações sobre a obra.

M: Primeiro a gente vai continuar falando o que? Escrevendo o resumo, e descrevendo a obra... descrevendo...

ML: Mas tem que contar a história toda. ML: Mas a gente tem que contar a história, tá ligada?

ML: É mesmo, num pode contar o final não. Tem que deixar o leitor com vontade de ver. 
ML: A introdução tá, tá chamando atenção, aí o povo vai querer assistir o vídeo.

M: Mas não precisa contar mais história, precisa opinar agora.

ML: Tenta concluir aí agora.

M: Concluir com opinião.

M: Aí agora vem nossa opinião.

M: A gente tem que indicar a obra.

M: Mas indica é no final.

M: Esse negócio de reflexão, a gente devia ter deixado pro último parágrafo, pra fazer a pessoa assistir o filme.

As falas supracitadas são de momentos em que a dupla planeja o que colocar no texto. Nos trechos selecionados, é possível identificar cinco aspectos que as estudantes julgam serem característicos do gênero resenha: (1) deve conter informações sobre a obra resenhada; (2) deve ter um resumo da obra; (3) deve conter a opinião do resenhador a respeito da obra; (4) deve-se indicar (ou não) a obra; (5) deve despertar o desejo do leitor pela obra resenhada. Os quatro primeiros aspectos apontados por elas nada mais são que os movimentos retóricos apontados por Motta-Roth e Hendges (2010). O quinto aspecto também está em conformidade com o que dizem essas autoras, que afirmam que o escrevente de uma resenha descreve e avalia uma obra buscando atender o leitor. Além disso, vemos que as escreventes apresentam alguns aspectos que, segundo elas, devem aparecer em uma resenha. Esses aspectos apontados por elas também estão em conformidade com a descrição esquemática das estratégias retóricas usadas no gênero resenha, proposta por Motta-Roth (1995 apud MOTTA-ROTH;HENDGES, 2010). Ao dizerem que, na introdução, é preciso falar sobre a obra e sobre os seus autores, as estudantes mencionam dois passos que a autora menciona como sendo partes do movimento de apresentar a obra: informar o tópico geral e/ou dar referências sobre o autor. Adiante, a dupla afirma a necessidade de escrever um resumo da obra, de descrevê-la, o que, para Motta-Roth, seria o passo dar uma visão geral da organização da obra, parte do movimento de descrever a obra. Por último, as universitárias comentam que, no final, deve-se opinar sobre a obra e indicá-la, aspectos que fazem parte dos movimentos de avaliar e (não) recomendar a obra resenhada.

Como vemos, as escolhas linguísticas, textuais e discursivas da dupla são determinadas, sobretudo, pelo conhecimento que ela detém a respeito dos aspectos característicos da resenha acadêmica. Esse conhecimento vai além da simples organização da forma canônica do texto; como podemos perceber, na produção da resenha, a dupla faz uma leitura crítica e construtiva do texto-base, sempre dialogando com o autor da obra. Conforme salienta Bakhtin, "Quanto mais dominamos os gêneros tanto mais livremente os empregamos, [...] realizamos de modo 
mais acabado o nosso livre projeto de discurso" (BAKHTIN, 2011, p. 285).

Nos exemplos apresentados, observamos que as estudantes demonstram ter entendimento do contexto de produção e recepção do texto, das características do discurso argumentativo e dos mecanismos linguísticos que materializam o gênero no qual estavam enunciando (MACHADO; LOUSADA; ABREU-TARDELLI, 2004). Em outras palavras, uma vez que já estão inseridos na prática acadêmica, essas estudantes universitárias se preocupam em utilizar maneiras de referenciar e textualizar seus saberes, de acordo com as situações e objetivos pleiteados por essa esfera.

Vejamos momentos da conversa que a dupla mantém entre si durante a elaboração textual que ilustram o que estamos dizendo:

ML: Então... O que que a gente vai fazer? M: Bom, primeiro a gente tem que... Como a gente é de computação, primeiro a gente tem que analisar a arte gráfica, (risos).

ML: É... Também a gente pode falar dessa parte.

M: É. Porque é uma animação, né?

ML: A gente fala da qualidade e tal.

ML: Mas perceba que, no final do vídeo, ela também está de preto. Ai depois você entende que ela tá botando a menina pra ir pra sala, bem assim, no início: "Você não vê que não é hora de tá fazendo isso?" M: É verdade. (Pausa) É verdade.
ML: Entendeu? (Pausa) Ou seja, enquanto tá todo mundo lá velando o corpo de alguém, sei lá, que é da vó dela, ela tem que ajudar nos serviços domésticos. M: É, porque a cena é reproduzida igualzinha no final.

ML: Hunrum.

(Pausa)

M: É verdade.

ML: Entendeu o que eu falei?

M: Hunrum. Entendi.

E ela se acomodou com a vida que levava...

ML: Hunrum.

M: Porque, por mais que a mãe dela pudesse ter obrigado ela a fazer isso, ela poderia ter feito diferente...

ML: Poderia ter feito outra coisa.

M: Mas se acomodou. Casou com o...

ML: Antoim (Risos)

M: Antoim (Risos)

ML: Então, vamo lá. Como é que a gente começa?

Nesses excertos, vemos que, diante da pergunta de ML sobre como iriam proceder para começar o texto, diante das exigências do gênero, $M$ decide que, como elas são da área de Ciências da Computação, deveriam analisar questões relativas à arte gráfica. No texto pronto, a ideia apreendida nessa discussão aparece em "com tons quentes e marcantes". Em seguida, é possível perceber que ainda discutindo sobre como deveriam iniciar o texto, procuram compreender o conteúdo global do filme. Vale lembrar que, segundo Marcuschi 
(2010), retextualizar implica inevitavelmente compreender o texto-base, ou seja, compreender também é requisito imprescindível para a produção de uma resenha. Podemos dizer que as escreventes, enquanto alunas universitárias do curso de Ciência da Computação, produzindo uma resenha acadêmica, buscam, primeiramente, compreender o texto-base, $\mathrm{e}$ daí, a partir do conhecimento que detém acerca do gênero, utilizam maneiras de referenciar e textualizar seus saberes para materializar o texto que escrevem. É possível afirmar, portanto, que, enquanto retextualizam o curta metragem, as estudantes demonstram um saber fazer e um saber dizer, conforme postulou Matencio (2002), visto que se apropriam de conceitos e procedimentos acadêmicos científicos e dos modos de referência e de textualização dos saberes típicos dessa esfera de produção.

Como dissemos anteriormente, segundo Bakhtin (2011), todas as esferas da atividade humana produzem enunciados concretos e únicos, de acordo com as condições específicas e as finalidades de cada uma dessas esferas. Sendo assim, todos os aspectos constituintes dos gêneros estão relacionados às esferas das quais cada um faz parte. Uma vez que a esfera acadêmica se constitui como um campo mais complexo e organizado da comunicação discursiva, podemos dizer que esta tende a elaborar gêneros discursivos secundários (complexos), que parecem não ter um vínculo imediato com a realidade concreta e com os enunciados reais alheios. Todavia, isso não significa que, nos gêneros da esfera acadêmica, não há uma comunicação discursiva viva, pois, como destaca Bakhtin, "Em cada enunciado [...] abrangemos, interpretamos, sentimos a intenção discursiva do discurso ou a vontade discursiva do falante, que determina o todo do enunciado, o seu volume e suas fronteiras" (BAKHTIN, 2011, p. 281).

Nos excertos supracitados, vimos que as estudantes, além de estabelecerem um diálogo contínuo entre si e com outros discursos (sobretudo com o texto-fonte), produzem a resenha acadêmica esperando uma compreensão ativamente responsiva (embora não imediata) por parte dos seus interlocutores. Além disso, no texto final da resenha, é possível perceber, interpretar e sentir a intenção discursiva do discurso e a vontade discursiva das escreventes.

Uma vez que consideramos a resenha acadêmica como um produto de retextualização, precisamos destacar, ainda, os mecanismos enunciativos por meio dos quais a dupla atribui ao texto-base a co-participação em sua retextualização, a saber: "O curta metragem Vida Maria [...] retrata a triste realidade das Marias", "Esta animação [...] descreve a vida de Maria José" e "Márcio Ramos, roteirista do curta, proporciona ao espectador". Esses mecanismos enunciativos utilizados pelas alunas estão em conformidade com o que diz Lima-Silva (2011) e mostram que, além de registrarem a leitura ou referirem-se a aspectos do 
texto-base, elas realizam uma série de operações textuais e discursivas. Segundo Matencio (2002), a função dessas operações é: 1) articular os parágrafos e períodos do texto; 2) iniciar segmentos em que são apresentadas as proposições do texto-base; 3 ) mostrar a posição do autor do texto-base; 4) mostrar a posição do (s) autor (es) da resenha em relação ao que é dito pelo autor do texto base e 5) estabelecer interlocução com o leitor da resenha. Como vemos, as estudantes utilizam esses mecanismos sempre no início de cada parágrafo, e, por meio de elementos como "o curta-metragem Vida Maria", "esta animação", "Márcio Ramos, roteirista do curta", e de verbos como "retrata", "descreve" e "proporciona", elas indicam o título da obra e a retomam, e atribuem ações ao produtor da obra e à própria obra, e, dessa maneira, apresentam as proposições do texto-base e mostram a posição do seu autor, estabelecendo, assim, uma interlocução com o leitor do texto que produzem.

Podemos observar que, na resenha acadêmica em questão, as escreventes estabelecem uma relação com o curta metragem, ao mesmo tempo em que se posicionam como avaliadoras da obra, o que nos permite dizer que elas têm conhecimento acerca do gênero e de suas funções nas práticas discursivas, ou seja, a dupla simultaneamente aponta a perspectiva dos produtores do curta metragem e da sua própria perspectiva. Além disso, fornece informações sobre o texto-base que julgam importantes, seguindo rigorosamente a estrutura retórica da resenha acadêmica.

Como é possível perceber, os dados processuais nos revelam detalhes da produção da resenha aos quais não teríamos acesso olhando apenas para o texto pronto, visto que, por meio deles, temos acesso a reflexões a respeito do texto-base e do gênero resenha que não aparecem efetivamente na versão final do texto. Dessa forma, podemos dizer que os dados processuais, juntamente com o texto pronto, são uma importante fonte de informação para se averiguar as operações que ocorrem no processo de retextualização.

\section{Conclusão}

Neste artigo, ancorados na abordagem de Matencio (2002) e Marcuschi (2010) a respeito da atividade retextualização, nos propusemos a descrever as operações textuais e discursivas no processo de retextualização de um curta-metragem para uma resenha acadêmica, buscando verificar de que maneira uma dupla de estudantes universitários estabelece uma relação com o curta metragem, a partir de estratégias linguísticas, textuais e discursivas com as quais ela constrói a macroestrutura de sua resenha acadêmica.

Primeiramente, ao observamos as escolhas feitas pelas estudantes em cada parágrafo da resenha que escreveram, pudemos verificar que elas conseguiram estabelecer um vínculo efetivo com 
o texto-base, embora, no $3^{\circ}$ parágrafo este vínculo não se mostre com muita clareza, visto que este é um parágrafo mais reflexivo, com opiniões pessoais das alunas a respeito da sociedade, e não especificamente sobre do curta metragem. Todavia, no $1^{\circ}, 2^{\circ}$ e $4^{\circ}$ parágrafos, a dupla apresenta e caracteriza o vídeo, narra a história da obra e descreve o que seriam, ao seu ver, proposições do texto-base.

Em seguida, levando em consideração os níveis de retextualização de uma resenha propostos por Souza e Silva (2017), observamos que, na resenha que analisamos, a descrição do conteúdo do texto-base se sobressai, visto que, em geral, a dupla de alunas caracteriza a obra, apresenta suas proposições e conta sua história. Entretanto, essa descrição se inter-relaciona com a apreciação da dupla resenhista sobre o texto-base em repetidas vezes, como em momentos em que as escreventes descrevem e avaliam a obra ao mesmo tempo.

Ainda, a partir de trechos da conversa mantida entre a dupla enquanto produzia a resenha, notamos que, na retextualização da resenha, as estudantes mantêm-se ligadas, necessariamente, a dois elementos: a estrutura retórica do gênero, e ao texto-base. É o que vemos nos trechos da conversa mantida pelas universitárias, em que elas comentam a respeito do que devem ou não colocar em cada parte do texto. Dessa forma, podemos afirmar que a dupla, enquanto retextualiza, demonstra um saber fazer e um saber dizer, conforme postulou Matencio (2002).
Seguindo os pressupostos de Bakhtin (2011), verificamos que, inseridas no campo acadêmico, as estudantes utilizam maneiras de referenciar e textualizar seus saberes, considerando as características e objetivos específicos dessa esfera, além de se preocuparem em utilizar adequadamente os elementos linguísticos e estruturais típicos da resenha acadêmica.

Podemos dizer, ainda que, na posição de sujeitos socialmente organizados, as estudantes realizam um diálogo contínuo entre si e com outros discursos, e elaboram a resenha acadêmica aguardando uma compreensão ativamente responsiva por parte dos seus interlocutores, 0 que faz com que esses percebam, interpretem e sintam a intenção discursiva do discurso e a vontade discursiva das escreventes. Sendo assim, é possível afirmar que, na resenha acadêmica, existe uma comunicação discursiva viva.

Vimos, também, que a dupla de estudantes se valeu de alguns mecanismos enunciativos para atribuir ao texto-base a coparticipação em sua retextualização. É o que observamos, por exemplo, nos trechos "O curta metragem Vida Maria [...] retrata a triste realidade das Marias", "Esta animação [...] descreve a vida de Maria José" e "Márcio Ramos, roteirista do curta, proporciona ao espectador", em que utilizam elementos de indicação e retomada à obra e ao seu produtor, e verbos que atribuem ações ao produtor do vídeo e ao próprio vídeo. Esses mecanismos mostraram que, além 
de registrarem a leitura ou referirem-se a aspectos do texto-base, as escreventes realizam uma série de operações textuais e discursivas.

Sendo assim, chegamos à conclusão de que a dupla conseguiu, em sua resenha, estabelecer uma relação com o curta metragem, ao mesmo tempo em que se posicionaram como avaliadores da obra, permitindo-nos afirmar que as estudantes têm conhecimento acerca do gênero e de suas funções nas práticas discursivas, o que é algo muito importante para o processo de retextualização, visto que, esse processo envolve relações entre gêneros, textos e discursos. Além disso, para retextualizar, é preciso se apropriar dos modos de referência e textualização dos saberes e dos procedimentos acadêmico-científicos.

Vale salientar, que grande parte das operações de retextualização que descrevemos só foram identificadas a partir dos dados processuais, que nos deram acesso a detalhes da produção da resenha aos quais não teríamos acesso apenas com o texto pronto. Portanto, os dados do processo de construção da resenha, juntamente com o texto final, foram de fundamental importância para o desenvolvimento desta análise.

\section{Academic writing: the review as product of retextualization}

\begin{abstract}
In this research paper, the academic review is considered as a product of retextualization. Anchored in Marcuschi (2010) and Matencio (2002), the retextualization is understood as a process of transformation of one text into another, involving linguistic, textual, discursive and cognitive aspects. Thereby, we intend to describe the textual and discursive operations involved in the process of retextualization of a short film for the writing of an academic review. For this, we will use an academic review written by two university students, and their procedural data, from the short film Vida Maria. The analysis pointed out that, in the review which was analyzed, our subjects had established a relation with the short film, at the same time that they positioned themselves as reviewers of the composition, maintaining, therefore, a link between the rhetorical structure of the genre and with the text-base.
\end{abstract}

Keywords: academic writing. Review. retextualization.

\section{Notas}

1 Os dados processuais utilizados nesta investigação fazem parte de um projeto de pesquisa intitulado "A relação entre estilo e gênero vista sob a perspectiva processual: desvendando segredos da criação", coordenado pela Profa. Dra. Márcia Helena de Melo Pereira (UESB/ PPGLin), que investiga o texto em seu status nascendi. Como nasce um texto? Essa é uma das questões que interessam ao projeto. Como sempre enunciamos tomando por base um gênero do discurso, seu conceito é fundamental 
para se discutir qualquer questão relacionada a textos. Sendo assim, procura-se investigar, também, questões estilísticas, tanto individuais quanto dos gêneros. Pergunta-se: é possível depreender um estilo de escrita próprio do escrevente, ou o estilo dos gêneros (no sentido bakhtiniano) prevalece sobre seu estilo? Portanto, a dupla em questão não escolheu o gênero com o qual deveria enunciar, nesse caso em específico. No entanto, Marcuschi lembra que "é impossível se comunicar verbalmente a não ser por algum gênero" (MARCUSCHI, 2010, p. 22).

2 MOTTA-ROTH, D. Rhetorical features and disciplinary cultures: A genre-based study of academy book reviews in linguistics, chemistry, and economics. 1995. Tese (Doutorado). Universidade Federal de Santa Catarina, Florianópolis.

\section{Referências}

ARAÚJO, Antônia Dilamar. Uma análise da polifonia discursiva em resenhas críticas acadêmicas. In: MEURER, José Luiz; MOTTA-ROTH, Desirée (Org.). Gêneros textuais e práticas discursivas: subsídios para o ensino da linguagem. Bauru- SP: EDUSC, 2002.

BAKHTIN, Mikhail. Estética da criação verbal. Introdução e tradução de Paulo Bezerra. 6 ed. São Paulo: Editora WMF Martins Fontes, 2011.

LIMA-SILVA, Ana Virgínia. A produção de resenha acadêmica no ensino superior. $R e$ vele, n. 02, jan. 2011.

MACHADO, Anna Rachel. A perspectiva interacionista sociodiscursiva de Bronckart. In: MEURER, José Luís; BONINI, Adair; MOTTA-ROTH, Désirée (Org.). Gêneros: teorias, métodos, debates. São Paulo: Parábola, 2005. p. 237-259.

MACHADO, Anna Rachel; LOUSADA, Eliane; ABREU-TARDELLI, Lília Santos. Resenha. São Paulo: Parábola Editorial, 2004.

MARCUSCHI, Luiz Antônio. Da fala para a escrita: atividades de retextualização. 10 eds. São Paulo: Cortez, 2010.
MATENCIO, Maria de Lourdes Meirelles. Atividades de retextualização em práticas acadêmicas: um estudo do resumo. Scrip$t a$, v. 6 , n. 11. Belo Horizonte: PUC Minas, p. 109-122, 2002.

MOTTA-ROTH, Desirée. A construção social do gênero resenha acadêmica. In: MEURER, José Luiz; MOTTA-ROTH, Desirée (Org.). Gêneros textuais e práticas discursivas: subsídios para o ensino da linguagem. BauruSP: Edusc, 2002. p. 77-108.

MOTTA-ROTH, Desirée; HENDGES, Graciela Rabuske. Produção textual na universidade. São Paulo: Parábola Editorial, 2010.

SOUZA, Clara Regina Rodrigues de; SILVA, Williany Miranda da. A resenha como produto de retextualização em (re)escrita acadêmica. Resvista Trama, v. 13, n. 28. Marechal Cândido Rondon/ Cascavel: Unioeste, p. 54-85, 2017.

SILVA, Jane Quintiliano Guimarães da; MATENCIO, Maria de Lourdes Meirelles. Retextualização: movimentos de aprendizagem. In: II Encontro Internacional Linguagem, Cultura e Cognição, Belo Horizonte/Campinas, 2003. Anais. Belo Horizonte/ Campinas: Faculdade de Educação da UFMG/ Faculdade de Educação da Unicamp, 2003. 